\title{
Anticancer activity of topical ointments with histone deacetylase inhibitor, trichostatin A
}

\author{
Agnieszka Chodkowska ${ }^{1, A-F}$, Alicja Bieńkowska ${ }^{1, C-E}$, Żaneta Słyk ${ }^{1, B}$, Joanna Giebułtowicz ${ }^{2, B, D}$, Maciej Małecki ${ }^{1, A, C, E, F}$ \\ ${ }^{1}$ Department of Applied Pharmacy, Faculty of Pharmacy, Medical University of Warsaw, Poland \\ ${ }^{2}$ Department of Bioanalysis and Drugs Analysis, Faculty of Pharmacy, Medical University of Warsaw, Poland \\ A - research concept and design; B - collection and/or assembly of data; C - data analysis and interpretation; \\ $D$ - writing the article; $E$ - critical revision of the article; $F$ - final approval of the article
}

Address for correspondence

Agnieszka Chodkowska

E-mail:agnieszka.chodkowska@wum.edu.pl

\section{Funding sources}

This work was partially supported by the National

Centre for Research and Development grant

(grant No. Strategmed1/233264/4/NCBR/2014,

MentorEYE).

\section{Conflict of interest}

None declared

Received on February 21, 2020

Reviewed on May 25, 2020

Accepted on June 22, 2020

Published online on September 7, 2020

\begin{abstract}
Background. Trichostatin A (TSA), being a strong specific histone deacetylase (HDAC) inhibitor, may lead to the inhibition of growth, differentiation and/or apoptosis of cells in a number of tumors. Semisolid drug formulations for topical release of anticancer agents may be an alternative strategy or a supplement of the systemic therapy.
\end{abstract}

Objectives. To prepare semisolid formulations with TSA to be used directly on the skin and to assess the anticancer effect in vivo on a mouse model with L1 neoplastic tumors.

Material and methods. Twenty-four formulations were prepared in the form of semisolid systems containing TSA as the active ingredient. Then, an in vitro study was performed concerning the release of the active substance from the prepared formulations. Four formulations were selected for in vivo studies: oil-in-water cream, hydrogel, w/o emulsion ointment on the absorptive hydrophobic medium, and o/w emulsion gel. The tumor size and mouse body weight were measured during the experiment. The tumors and healthy skin of the mice were assessed regarding the skin barrier function with the Corneometer and Tewameter probes.

Results. The semisolid formulation with TSA applied on the skin reduced the growth of neoplastic tumors as compared with the control group. This is especially pronounced in the case of w/o emulsion ointment and $0 / w$ emulsion gel. The Corneometer shows that neoplastic tumor growth and formulations on the skin have no effect on the skin condition in comparison with the mouse skin without tumor. The measurement performed with the Tewameter has revealed impaired skin barrier function of neoplastic tumors.

Conclusions. Semisolid formulations with TSA fit well in the mainstream of research into topical medicines applied directly on neoplastic tumors, which may support and supplement current oncological treatment.

Key words: trichostatin A, anticancer topical formulations, ointments, skin cream, cancer applied pharmacy

Cite as

Chodkowska A, Bieńkowska A, Słyk Ż, Giebułtowicz J, Małecki M. Anticancer activity of topical ointments with histone deacetylase inhibitor, trichostatin A. Adv Clin Exp Med. 2020;29(9):1039-1049. doi:10.17219/acem/124439

DOI

10.17219/acem/124439

Copyright

Copyright by Author(s)

This is an article distributed under the terms of the

Creative Commons Attribution 3.0 Unported (CC BY 3.0)

(https://creativecommons.org/licenses/by/3.0/) 


\section{Introduction}

Cancer is one of the main causes of death in the world. In developed countries, it is the $2^{\text {nd }}$ cause of death, after cardiovascular diseases. The number of new cases of cancer and cancer-related deaths in the world is increasing every year. According to Globocan, in 2018, the incidence of cancer was 18.1 million, causing the death of 9.6 million people worldwide. It is estimated that in 2040, the number of new cases of cancer will be 29.5 million. ${ }^{1}$ On the basis of the Polish National Cancer Registry, 164,875 of new cases of cancer and 99,644 cancer-related deaths were reported in Poland in 2017. The cancer morbidity rate in Poland has increased by 185,630 cases in 2018 and 113,388 deaths in 2018, according to Globocan. ${ }^{1,2}$ Strong emphasis is placed on early detection of neoplastic diseases combined with adequate treatment. For the last 20 years, anticancer therapy has been undergoing transformation from traditional cytotoxic drugs to a molecular targeted therapy. ${ }^{3,4}$ Currently, anticancer therapy is primarily based on the use of alkylating agents, antimetabolites, plant alkaloids, and anticancer antibiotics. Recently, there has been much discussion regarding the possibility of using epigenetic inhibitors. It has been shown that epigenetic regulation of gene expression is an essential mechanism which, if disturbed, leads to the development of cancer. The mechanisms of epigenetic control involve changes in the expression of genes key to carcinogenesis. Histone deacetylase inhibitors (HDIs) are considered to be used as new generation anticancer drugs, which induce increased histone acetylation. ${ }^{5,6}$ Trichostatin A (TSA) inhibits histone deacetylase (HDAC). The inhibitory activity involves chelation of zinc (II) ion by the hydroxamic acid group in TSA in the HDAC active site. ${ }^{7}$ Trichostatin A was first described as an antifungal antibiotic in $1976 .{ }^{8}$ It shows the activity of a non-competitive, reversible inhibitor of HDAC activity at low nanomoles concentrations. ${ }^{9}$ There are reports indicating that TSA, being a strong specific HDAC inhibitor, may lead to the inhibition of growth, differentiation and/or apoptosis of cells in a number of tumors. ${ }^{10-14}$ Recently, it has been shown that TSA inhibits angiogenesis by reducing the expression of oxidase 4 (Nox4), which is inhibited by p300-histone acetyltransferase ((p300-HAT)-dependent pathway). This mechanism may be used to reduce angiogenesis in relation to diabetic retinopathy, neoplastic changes and developmental anomalies. ${ }^{15}$ The studies also suggest that TSA may have a therapeutic effect on cancerous cells in combination with radiotherapy, chemotherapy or hormonotherapy. ${ }^{16-19}$ Regarding the pharmaceutical form used in oncology, injection forms are currently predominant. New forms of oncological drugs include subcutaneous implants (Zoladex, Leuprostin) or intracranial implants with carmustine (e.g., Gliadel). The cytostatic agent 5 -fluorouracil is used in dermatology in the form of liquid for papillae (Verrumal) and as ointment (Efudix) in the treatment of actinic and solar keratosis, basal cell carcinoma, Bowen's disease, and precancerous skin conditions. Transdermal administration is necessary to ensure prolonged release of medicines and maintain the local effect. ${ }^{20,21}$ The present paper focuses on semisolid formulations with TSA. The aim of the studies was to develop TSA formulations to be used topically, and to assess the anticancer activity of the obtained preparations in vivo.

\section{Material and methods}

\section{Development of the formula and preparation of semisolid formulations with TSA}

Adequate media were selected for the initial studies, and 24 formulations were developed. Pharmacopoeial ingredients, compound ready-made media available for a pharmaceutical formulation and new polymer-based media were selected. The compositions of all formulations are presented in Table 1. The following formulations were prepared: w/o emulsions, o/w emulsions, hydrogels, and o/w emulsion gel. The obtained formulations were examined organoleptically during and after their preparation. They were assessed with regard to appearance, consistency and spreading. Semisolid formulations containing ready-made pharmacopoeial media used in the experiment (forming w/o emulsions - No. 1, 2, 8, and 10) and industrial ones (o/w emulsions - No. 3 and 24) were prepared with the use of the mixing system - Cito Unguator ${ }^{\circledR} \mathrm{e} / \mathrm{s}$ (Eprus, BielskoBiała, Poland). Formulations in the form of o/w emulsions No. 6, 7, 9, and 19 were prepared by melting the ingredients of the oil phase in the water bath ${ }^{22}$ (LaboPLAY Type W 410; LaboPLAY, Bytom, Poland) and emulating water with the ingredients dissolved therein, then mixing with the use of the mixing system (Cito Unguator ${ }^{\circledR} \mathrm{e} / \mathrm{s}$ ). Formulations in the form of $\mathrm{o} / \mathrm{w}$ emulsions (No. 4 and 5), gels (No. 11-18, 20, 22, and 23) and o/w emulsion gel (No. 21) containing gelling, concentrating and stabilizing agents were prepared using standard methods ${ }^{23-25}$ and mixing with the use of the mixing system (Cito Unguator $^{\circledR} \mathrm{e} / \mathrm{s}$ ). Directly before the study, the TSA solution was added to the prepared media. $0.01 \%$ formulations with TSA were prepared for in vitro studies. The TSA (Trichostatin A - Sigma-Aldrich cat. No. T8552; Sigma-Aldrich, St. Louis, USA) solution was prepared by dissolution of $1 \mathrm{mg}$ of TSA in $0.5 \mathrm{~mL}$ dimethyl sulfoxide (DMSO) (Sigma-Aldrich). From the obtained solution, $50 \mu \mathrm{L}$ was collected; then, $500 \mu \mathrm{L}$ of phosphate-buffered saline (PBS; Gibco, Waltham, USA) was added. One hundred microliters of thus prepared solution contained $18.18 \mu \mathrm{g}$ of TSA (in DMSO+PBS). 


\section{In vitro study of TSA release from the prepared formulations}

The studies on release involved semisolid formulations with TSA prepared in accordance with the composition specified in Table 1 . The compositions of 24 formulations containing TSA were developed and a study of the active substance release from the prepared formulations was conducted. Eighteen formulations containing TSA were selected, in which the released TSA was quantified. The formulations with no detected released TSA were rejected from further studies. Then, the formulations were tested for release in order to select semisolid TSA formulations for in vivo studies on a murine model. In order to study the prepared formulations, a method of TSA release in vitro was developed. The studies were conducted with the use of 24-well plates with polyethylene teraphthalate (PET) membrane inserts with a diameter of $6.5 \mathrm{~mm}$; the pores were $8 \mu \mathrm{m}$ (BD BioCoat Matrigel Invasion Chambers; Becton Dickinson Biosciences, San Jose, USA). The inserts were filled with $200 \mathrm{mg}$ of TSA formulation (0.01\%), and then the wells were filled with $300 \mu \mathrm{L}$ of acceptor liquid (Aqua pro injectione; Polpharma, Starogard Gdański, Poland) (Fig. 1).

The study was conducted for $6 \mathrm{~h}$ in an incubator (POLEKO Aparatura, Wodzisław Śląski, Poland) at $37^{\circ} \mathrm{C}$. After $6 \mathrm{~h}$, the samples were collected and measured spectrophotometrically with UV-VIS (Quawell Q 5000, $\lambda=264$ nm; Quawell, San Jose, USA) and with liquid chromatography combined with mass spectrometry (LC-MS/MS). Instrumental analysis was performed using Agilent 1260 Infinity (Agilent Technologies, Santa Clara, USA) equipped with a degasser, autosampler and binary pump, coupled to a Hybrid Triple Quadrupole/Linear Ion trap mass spectrometer (QTRAP $^{\circledR} 4000$; AB SCIEX, Framingham, USA). The curtain gas, ion source gas 1 , ion source gas 2 , and collision gas (all high purity nitrogen) were set at $240 \mathrm{kPa}, 410 \mathrm{kPa}$, $275 \mathrm{kPa}$, and "medium" instrument units, respectively. The ion spray voltage and source temperature were $5500 \mathrm{~V}$ and $600^{\circ} \mathrm{C}$, respectively. Chromatographic separation was achieved with a Kinetex RP-18 column (100 mm, 4.6 mm,

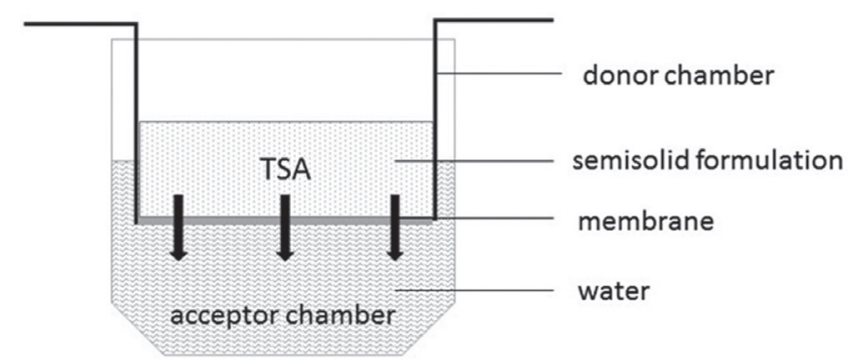

Fig. 1. Membrane model for TSA release. The insert was filled with $200 \mathrm{mg}$ of TSA formulation, then $300 \mu \mathrm{L}$ of the acceptor liquid - Aqua pro injectione - was added to the well. After $\mathrm{t}=6 \mathrm{~h}$, a sample was collected and measured with UV-VIS and LCMS/MS particle size $2.6 \mu \mathrm{m}$ ) supplied by Phenomenex (Torrance, USA). The column was maintained at $40^{\circ} \mathrm{C}$ at a flow rate of $0.5 \mathrm{~mL} / \mathrm{min}$. The mobile phases consisted HPLC-grade water with $0.2 \%$ formic acid as eluent $\mathrm{A}$ and acetonitrile with $0.2 \%$ formic acid as eluent $\mathrm{B}$. The gradient B was as follows: $0 \mathrm{~min} \mathrm{30 \% ;} 0.5 \mathrm{~min} \mathrm{30 \% ;} 3 \mathrm{~min} \mathrm{95 \% ;} \mathrm{and}$ $7 \mathrm{~min} 95 \%$. A total of $10 \mu \mathrm{L}$ of samples were diluted with $50 \%$ acetonitrile and mixed with M344 (internal standard; Santa Cruz Biotechnology, Santa Cruz, USA) to a final concentration of $0.1 \mu \mathrm{g} / \mathrm{mL}$ in $200 \mu \mathrm{L}$ of solution. The volume of injection was $5 \mu \mathrm{L}$. The target compounds were analyzed in multiple reaction monitoring (MRM) mode, monitoring 2 transitions between the precursor ion and the most abundant ions for each compound was 303->148 (quantitative transition) and 303->120 (qualitative transition) for TSA, and 308->148 (quantitative transition) and 308->120 (qualitative transition) for M344. The compound parameters for quantitative transitions viz. declustering potential (DP), collision energy (CE), entrance potential (EP), and collision exit potential (CXP) were 66, 33, 10, and $10 \mathrm{~V}$, respectively, for TSA, and 61, 25, 10, and $14 \mathrm{~V}$, respectively, for M344.

The results of TSA release marked UV-VIS and LC-MS/ MS are presented in Fig. 2.

\section{Examination of anticancer activity of semisolid TSA formulations in vivo in Balb/c mice with L1 tumor}

On the basis of TSA release results, organoleptic assessment and an assessment of the characteristics of the L1 tumor, the following 4 formulations were selected for in vivo studies: $5,10,18$, and 21 . The studies were conducted on laboratory Balb/c mice with the approval of the Bioethics Committee of the Medical University of Warsaw, Poland (approval No. 160/2016). The sites on the mouse back, in the neck area, were shaved before starting the experiments. The females of Balb/c mice (weight: 18-25 g) were administered subcutaneously (s.c.) with cancer cells of murine sarcoma L1 $3 \times 10^{5} / 0.1 \mathrm{~mL}$ PBS per mouse. ${ }^{26}$ The cells were obtained from standard in vitro culture of L1 line. Then, when tumors with a diameter of 1-10 $\mathrm{mm}$ appeared, the mice were divided into adequate groups $(\mathrm{n}=3)$ and the tests were initiated. To perform the tests, TSA was dissolved in DMSO, and PBS was added to achieve $100 \mu \mathrm{g}$ TSA in $100 \mu \mathrm{L}$ DMSO + PBS $(1 \mathrm{mg}$ TSA $+200 \mu \mathrm{L}$ DMSO $+800 \mu \mathrm{L} \mathrm{PBS}) .{ }^{27}$ The TSA solution was administered as intratumor injection and into the semisolid formulations. The active substance (TSA) was introduced to the semisolid formulations immediately before use. Four groups of mice were treated with the selected TSA formulations No. 5, 10, 18, and 21 at a dose of $100 \mu \mathrm{g}$ TSA/200 mg formulation/mouse/day (divided into 2 doses, three-hour interval) for 5 consecutive days. The mice on which the formulation was applied 
Table 1. Compositions of the design semisolid formulations: No. 1, 2, 8, and 10 - emulsions w/o; No. 3-7, 9, 19, and 24 - emulsions o/w; No. 11-18, 20, 22, and 23 - gels; No. 21 - o/w emulsion gel. Trichostatin A was introduced ex tempore at a dose of $0.01 \%$ for in vitro release and at a dose of $0.05 \%$ for in vivo animal tests

\begin{tabular}{|c|c|c|c|c|c|c|c|c|c|c|c|c|}
\hline \multirow{2}{*}{ Composition } & \multicolumn{12}{|c|}{ Formulation No. } \\
\hline & 1 & 2 & 3 & 4 & 5 & 6 & 7 & 8 & 9 & 10 & 11 & 12 \\
\hline $\begin{array}{l}\text { Unguentum Cholesteroli } \\
\text { (Pharma-Cosmetic) }\end{array}$ & $50 \%$ & & & & & & & & & & & \\
\hline $\begin{array}{l}\text { Euceryna (Fagron) } \\
\text { Unguentum Eucerini I }\end{array}$ & & $50 \%$ & & & & & & & & & & \\
\hline Lekobaza (Pharma-Cosmetic) & & & $50 \%$ & & & & & & & & & \\
\hline $\begin{array}{l}\text { Vaselinum hydrophylicum } \\
\text { (Pharma-Cosmetic) }\end{array}$ & & & & & & & & $50 \%$ & & & & \\
\hline Methocel ${ }^{\circledR} 90 \mathrm{HG}$ (Sigma-Aldrich) & & & & $0.5 \%$ & $0.25 \%$ & & & & & & & \\
\hline $\begin{array}{l}\text { Paulister-SG } \\
\text { Glyceryl Stearate (Paulika) }\end{array}$ & & & & $10 \%$ & $10 \%$ & $12 \%$ & & & $2.5 \%$ & & & \\
\hline $\begin{array}{l}\text { Isopropyl Myristate } \\
\text { (Paulika) }\end{array}$ & & & & $10 \%$ & $10 \%$ & & & & & & & \\
\hline $\begin{array}{l}\text { Karinol-CS } \\
\text { Cetearyl Alcohol (Paulika) }\end{array}$ & & & & & & $2.25 \%$ & & & & & & \\
\hline $\begin{array}{l}\text { Karinol-C } \\
\text { Cetyl Alcohol (Paulika) }\end{array}$ & & & & & & & $5 \%$ & & $5 \%$ & & & \\
\hline Stearic acid (WarChem) & & & & & & & $13 \%$ & & $5 \%$ & & & \\
\hline $\begin{array}{l}\text { Cera alba } \\
\text { (Pharma-Cosmetic) }\end{array}$ & & & & & & & & & $2.5 \%$ & & & \\
\hline $\begin{array}{l}\text { Vaselinum album } \\
\text { (Aflofarm) }\end{array}$ & & & & & & & & & $10 \%$ & $12.5 \%$ & & \\
\hline $\begin{array}{l}\text { Lanolinum anhydricum } \\
\text { (Pharma-Cosmetic) }\end{array}$ & & & & & & & & & & $37.5 \%$ & & \\
\hline $\begin{array}{l}\text { Carboxymethylcellulose sodium } \\
\text { (Sigma-Aldrich) }\end{array}$ & & & & & & & & & & & $2 \%$ & $2 \%$ \\
\hline $\begin{array}{l}\text { Sodium dodecyl sulfate } \\
\text { (Sigma-Aldrich) }\end{array}$ & & & & & & & $5 \%$ & & & & & \\
\hline Triethanoloamine (POCH) & & & & & & & & & $2.5 \%$ & & & \\
\hline $\begin{array}{l}\text { Glycerolum 85\% } \\
\text { (Pharma-Cosmetic) }\end{array}$ & & & & & & & & & & & $10 \%$ & \\
\hline $\begin{array}{l}\text { Propylene Glycol } \\
\text { (WarChem) }\end{array}$ & & & & & & & & & & & & $10 \%$ \\
\hline $\begin{array}{l}\text { Trichostatin A (Sigma-Aldrich) } \\
\text { - in vitro }\end{array}$ & $0.01 \%$ & $0.01 \%$ & $0.01 \%$ & $0.01 \%$ & $0.01 \%$ & $0.01 \%$ & $0.01 \%$ & $0.01 \%$ & $0.01 \%$ & $0.01 \%$ & $0.01 \%$ & $0.01 \%$ \\
\hline $\begin{array}{l}\text { Trichostatin A (Sigma-Aldrich) } \\
\text { - in vivo }\end{array}$ & $0.05 \%$ & $0.05 \%$ & $0.05 \%$ & $0.05 \%$ & $0.05 \%$ & $0.05 \%$ & $0.05 \%$ & $0.05 \%$ & $0.05 \%$ & $0.05 \%$ & $0.05 \%$ & $0.05 \%$ \\
\hline $\begin{array}{l}\text { Aqua pro injectione } \\
\text { (Polpharma) }\end{array}$ & q.s. & q.s. & q.s. & q.s. & q.s. & q.s. & q.s. & q.s. & q.s. & q.s. & q.s. & q.s. \\
\hline
\end{tabular}

topically were kept separately and observed for $1 \mathrm{~h}$ until the formulation was absorbed. The control groups were treated in the same way with semisolid formulations No. $5,10,18$, and 21 without TSA. Two groups of mice received TSA intratumor injection $(100 \mu \mathrm{g}$ TSA $/ 100 \mu \mathrm{L}$ DMSO+PBS (C3)) and solvent intratumor injection $(100 \mu \mathrm{L}$ DMSO+PBS (C2)). The injections were given once daily, on the $1^{\text {st }}, 3^{\text {rd }}$ and $5^{\text {th }}$ day of the study. Also, a separate control group was formed, including mice not treated with the formulations (C1). Every day throughout the study all the mice were weighed and the tumors were measured with a caliper (Topex). The tumors were measured in 2 dimensions, perpendicularly. The tumor volume $(v)$ was calculated using the formula, where $(x \leq y)^{28,29}$ :

$$
v=x^{2} \times y \times(\pi / 6) .
$$

Examination of skin moisture and transepidermal water loss (TEWL) was performed with the probes Corneometer ${ }^{\circledR}$ CM 825 and Tewameter ${ }^{\circledR}$ TM 300. ${ }^{30,31}$

On the $1^{\text {st }}$ and $8^{\text {th }}$ day of the experiment, the skin on tumors and the healthy skin of mice were assessed with the Multi Probe Adapter (MPA) Systems measuring device and with the probes Corneometer ${ }^{\circledR}$ CM 825 
Table 1. Compositions of the design semisolid formulations: No. 1, 2, 8, and 10 - emulsions w/o; No. 3-7, 9, 19, and 24 - emulsions o/w; No. 11-18, 20, 22, and 23 - gels; No. 21 - o/w emulsion gel. Trichostatin A was introduced ex tempore at a dose of $0.01 \%$ for in vitro release and at a dose of $0.05 \%$ for in vivo animal tests - cont.

\begin{tabular}{|c|c|c|c|c|c|c|c|c|c|c|c|c|}
\hline \multirow{2}{*}{ Composition } & \multicolumn{12}{|c|}{ Formulation No. } \\
\hline & 13 & 14 & 15 & 16 & 17 & 18 & 19 & 20 & 21 & 22 & 23 & 24 \\
\hline Stearic acid (WarChem) & & & & & & & $12.5 \%$ & & & & & \\
\hline $\begin{array}{l}\text { Karinol-CS } \\
\text { Cetyl Alcohol (Paulika) }\end{array}$ & & & & & & & $5 \%$ & & & & & \\
\hline Methoce $l^{\circledR} 90 \mathrm{HG}$ (Sigma-Aldrich) & $3 \%$ & $3 \%$ & & & & & & & & & & \\
\hline $\begin{array}{l}\text { Carbopol }{ }^{\mathbb{1}} \text { Ultrez } 10 \text { (Lubrizol) } \\
\text { Carbomer }\end{array}$ & & & $1 \%$ & $1 \%$ & $1 \%$ & $1 \%$ & & & & & & \\
\hline Sepineo P 600 (Seppic) & & & & & & & & $4 \%$ & $3 \%$ & & & \\
\hline Sepineo D.E.R.M. (Seppic) & & & & & & & & & & $1.5 \%$ & $1.5 \%$ & \\
\hline $\begin{array}{l}\text { Pentravan }{ }^{\circledR} \text { (Fagron) } \\
\text { oil-in-water emulsion base }\end{array}$ & & & & & & & & & & & & $50 \%$ \\
\hline $\begin{array}{l}\text { Glicerol Glycerolum 85\% } \\
\text { (Pharma-Cosmetic) }\end{array}$ & $10 \%$ & & $10 \%$ & & $10 \%$ & & & & & & & \\
\hline Propylene Glycol (WarChem) & & $10 \%$ & & $10 \%$ & & $10 \%$ & & & & & $10 \%$ & \\
\hline Triethanoloamine (POCH) & & & $0.8 \%$ & $0.8 \%$ & & & & & & & & \\
\hline $\begin{array}{l}10 \% \mathrm{NaOH} \text { Sodium hydroxide } \\
\text { (Chempur) }\end{array}$ & & & & & $2.5 \%$ & $2.5 \%$ & & & & & & \\
\hline $\begin{array}{l}\text { Sodium dodecyl sulfate } \\
\text { (Sigma-Aldrich) }\end{array}$ & & & & & & & $2.5 \%$ & & & & & \\
\hline $\begin{array}{l}\text { Oleum Amygdalae dulcium } \\
\text { (Profarm) }\end{array}$ & & & & & & & & & $20 \%$ & & & \\
\hline $\begin{array}{l}\text { Trichostatin A (Sigma-Aldrich) } \\
\text { - in vitro }\end{array}$ & $0.01 \%$ & $0.01 \%$ & $0.01 \%$ & $0.01 \%$ & $0.01 \%$ & $0.01 \%$ & $0.01 \%$ & $0.01 \%$ & $0.01 \%$ & $0.01 \%$ & $0.01 \%$ & $0.01 \%$ \\
\hline $\begin{array}{l}\text { Trichostatin A (Sigma-Aldrich) } \\
\text { - in vivo }\end{array}$ & $0.05 \%$ & $0.05 \%$ & $0.05 \%$ & $0.05 \%$ & $0.05 \%$ & $0.05 \%$ & $0.05 \%$ & $0.05 \%$ & $0.05 \%$ & $0.05 \%$ & $0.05 \%$ & $0.05 \%$ \\
\hline $\begin{array}{l}\text { Aqua pro injectione } \\
\text { (Polpharma) }\end{array}$ & q.s. & q.s. & q.s. & q.s. & q.s. & q.s. & q.s. & q.s. & q.s. & q.s. & q.s. & q.s. \\
\hline
\end{tabular}

Methoce $\left.\right|^{\circledR} 90 \mathrm{HG}$ - hydroxypropylmethylcellulose; Sepineo P 600 - acrylamide/sodium acryloyldimethyl taurate copolymer/isohexadecane and polysorbate 80; Sepineo D.E.R.M. - hydroxyethyl acrylate/sodium acryloyldimethyl taurate copolymer; q.s. - quantum satis (just far enough).

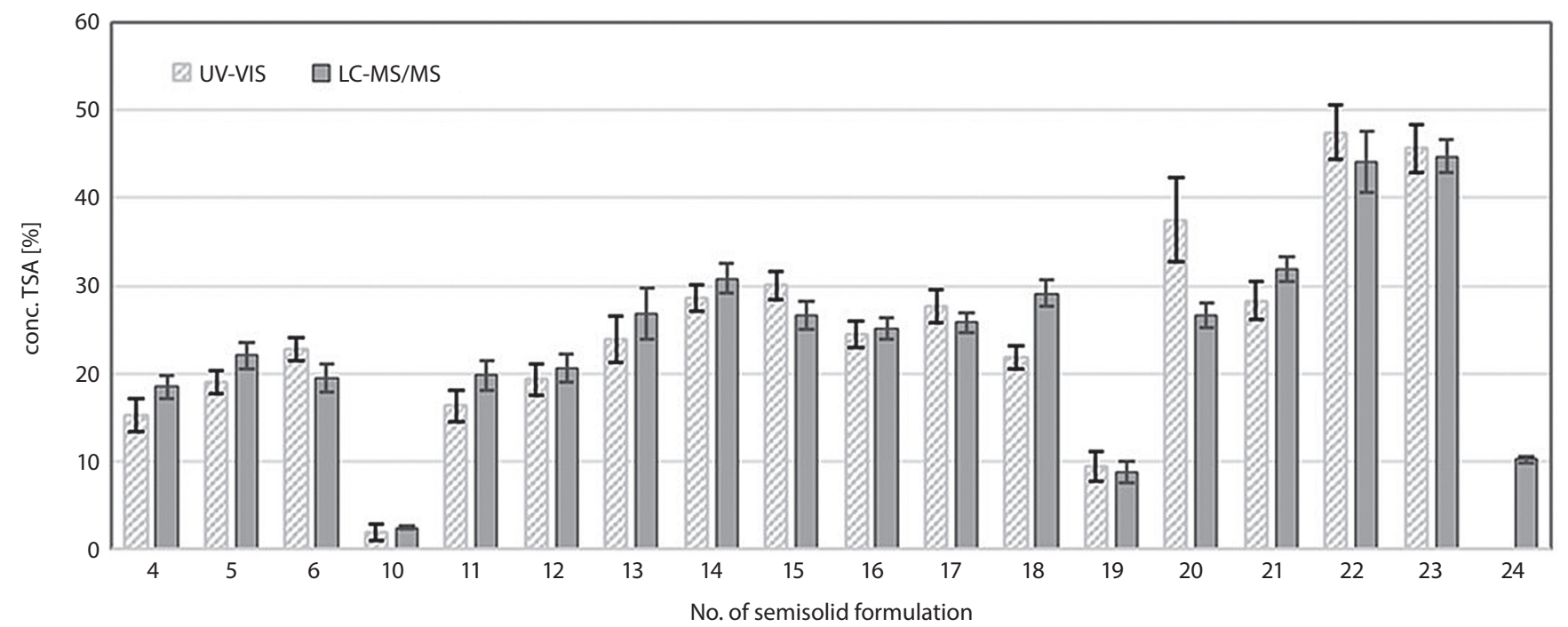

Fig. 2. Amount of TSA\% released from semisolid formulations after $6 \mathrm{~h}(\mathrm{n}=7)$ 
and Tewameter ${ }^{\circledR}$ TM 300 (Courage+Khazaka Electronic $\mathrm{GmbH}$, Cologne, Germany). The skin on neoplastic tumors and healthy skin surrounding the tumor were assessed. Hair was removed from the skin the day before the measurements. Then, the mice were euthanized, and the tumors and skin were collected for further studies.

The measurement of skin humidity with the Corneometer probe is based on a recognized international volumetric method. It provides confirmed and well-confirmed measurements of skin hydration. ${ }^{32,33}$ The Tewameter probe was used to assess TEWL without impairing the skin microenvironment. The Tewameter probe measures the density gradient of the water evaporation from the skin indirectly by the sensors of temperature and relative humidity, with the use of open chamber diffusion technique. The measurement of the water evaporation from the skin is the basic parameter in the assessment of the epidermal barrier function. ${ }^{34}$

\section{Statistical evaluation}

The studies were performed in accordance with the protocol approved by the Bioethics Committee of the Medical University of Warsaw (approval No. 160/2016). The results are presented in the form of mean and standard deviation (SD). Statistical significance $(p<0.05)$ of differences between the groups was analyzed with the use of one-way analysis of variance (ANOVA). The post hoc Tukey's test was used. Statistical significance was assessed with the use of GraphPad Prism v. 7 software (GraphPad Software, San Diego, USA). Statistically significant differences are marked with asterisks ( ${ }^{*} \mathrm{p}<0.05$; *** $\left.\mathrm{p}<0.01 ;{ }^{* * * *} \mathrm{p}<0.001\right)$

\section{Results}

\section{Preparation of semisolid formulations}

Semisolid formulations were developed with the use of ingredients available on the market. Ready-made media and pharmacopoeial ingredients used in the field of pharmacy were selected: Unguentum cholesteroli, Unguentum eucerini, Vaselinum hydrophyllicum, Vaselinum album, Lanolinum; industrial media: Lekobaza, Pentravan; gelling, concentrating and stabilizing substances: Carboxymethylcellulose sodium, Carbomer, Hydroxypropylmethylcellulose, Sepineo P600, and Sepineo D.E.R.M. Organoleptic analysis was performed during and after preparation. The formulations were assessed with regard to appearance, consistency and spreading. Twenty-four formulations were obtained: No. 1, 2, 8, and 10 - w/o emulsions; No. 3, 4, $5,6,7,9,19$, and $24-$ o/w emulsions; No. 11-18, 20, 22, and 23 - gels; and No. 21 - o/w emulsion gel (Table 1). The obtained formulations were homogeneous, had adequate consistency and spread well.

\section{Assessment of TSA release from semisolid formulations}

A test of TSA release from the obtained formulations was conducted. For this purpose, a method of in vitro TSA release was developed. The samples were measured spectrophotometrically with UV-VIS and with LC-MS/MS. The measurements performed with these 2 methods were comparable for most of the formulations (Fig. 2). The formulations No. 1, 2, 3, 8, and 9 were rejected, since there was no TSA release as measured using LC-MS/MS and there were difficulties with the UV-VIS measurement. Eighteen semisolid formulations were selected, and the release tests were performed again. On the basis of the release tests, the following formulations were selected for in vivo studies: No. 5 - o/w emulsion with a concentrating and stabilizing substance (hydroxypropylmethylcellulose) ${ }^{35}$; No. 18 - hydrogel with propylene glycol, which increases skin penetration of the formulation and prolongs its stability ${ }^{36}$; and No. 21 - o/w emulsion gel based on polymers and almond oil. ${ }^{24,25}$ The w/o emulsion ointment on the absorptive hydrophobic medium No. 10 was qualified for in vivo studies due to its occlusive properties, which could increase skin penetration by TSA.

\section{Assessment of anticancer activity of semisolid TSA formulations in vivo in Balb/c mice}

Everyday throughout the study (8 days) the mice were weighed and the tumor size was measured. No significant change in the mouse body weight was observed during the study. Rubbing the semisolid formulations with TSA in the tumors and intratumor TSA injections had no effect on the body weight of the mice. The tumors were measured in all the mice with a caliper for 8 days. The results are summarized in Table 2. It shows that the tumors treated with TSA formulations grow more slowly than the tumors treated with non-TSA formulations. The growth of tumors treated with TSA formulations was lower than in the corresponding control groups. Control tumors which were not treated with TSA formulations showed a regular growth. The tumors treated with TSA grew slowly, and their growth was inhibited.

\section{Assessment of skin hydration and TEWL with the probes Corneometer ${ }^{\circledR} \mathrm{CM} 825$ and Tewameter ${ }^{\circledR}$ TM 300}

A study with the Corneometer ${ }^{\mathbb{B}}$ CM 825 and Tewame$\operatorname{ter}^{\mathbb{B}}$ TM 300 probes was conducted on the $1^{\text {st }}$ day of the experiment, before testing the mice and on the last day, prior to autopsy. ${ }^{36}$ The skin on neoplastic tumors and the healthy skin surrounding the tumor were assessed. Hair was removed from the skin the day before the measurements. The measurement of skin humidity is based 
Table 2. Assessment of anticancer activity of semisolid TSA formulations in Balb/c mice with L1 tumor. Measurement of tumor volume $v$ [mm ${ }^{3}$ ]

\begin{tabular}{|c|c|c|c|c|c|c|c|c|}
\hline Formulation & Day 1 & Day 2 & Day 3 & Day 4 & Day 5 & Day 6 & Day 7 & Day 8 \\
\hline $\mathrm{C} 1$ & 41.6 & 41.6 & 78 & 131.04 & 203.84 & 229.32 & 520 & 692.12 \\
\hline C1 & 41.6 & 41.6 & 91 & 168.48 & 229.32 & 366.08 & 366.08 & 463.32 \\
\hline C1 & 18.72 & 49.92 & 131.04 & 421.2 & 421.2 & 572 & 572 & 692.12 \\
\hline C2 & 421.2 & 421.2 & 624 & 817.96 & 817.96 & 880.88 & 943.8 & 943.8 \\
\hline C2 & 112.32 & 112.32 & 178.36 & 266.24 & 266.24 & 299.52 & 299.52 & 421.2 \\
\hline C2 & 65 & 65 & 149.76 & 272.636 & 203.84 & 299.52 & 421.2 & 624 \\
\hline C3 & 463.32 & 399.36 & 399.36 & 547.56 & 547.56 & 631.8 & 780 & 780 \\
\hline C3 & 229.32 & 421.2 & 332.8 & 463.32 & 299.52 & 463.32 & 505.44 & 505.44 \\
\hline C3 & 299.52 & 299.52 & 203.84 & 266.24 & 379.08 & 421.2 & 421.2 & 421.2 \\
\hline 5 & 78 & 78 & 78 & 131.04 & 203.84 & 366.08 & 366.08 & 463.32 \\
\hline 5 & 78 & 112.32 & 131.04 & 203.84 & 266.24 & 299.52 & 299.52 & 332.8 \\
\hline 5 & 65 & 65 & 65 & 112.32 & 178.36 & 266.24 & 266.24 & 299.52 \\
\hline $5+\mathrm{TSA}$ & 149.76 & 203.84 & 203.84 & 203.84 & 203.84 & 203.84 & 421.2 & 421.2 \\
\hline $5+\mathrm{TSA}$ & 0.52 & 0.52 & 0.52 & 0.52 & 0.52 & 0.52 & 0.52 & 0.52 \\
\hline $5+\mathrm{TSA}$ & 14.04 & 14.04 & 18.72 & 18.72 & 18.72 & 18.72 & 41.6 & 41.6 \\
\hline 18 & 254.8 & 366.08 & 463.32 & 463.32 & 624 & 676 & 676 & 817.96 \\
\hline 18 & 299.52 & 299.52 & 332.8 & 421.2 & 421.2 & 572 & 624 & 676 \\
\hline 18 & 149.76 & 203.84 & 254.8 & 254.8 & 280.28 & 366.08 & 505.44 & 624 \\
\hline $18+$ TSA & 6.24 & 6.24 & 18.72 & 18.72 & 18.72 & 18.72 & 18.72 & 41.6 \\
\hline $18+$ TSA & 112.32 & 112.32 & 78 & 78 & 78 & 78 & 78 & 91 \\
\hline $18+$ TSA & 203.84 & 203.84 & 203.84 & 203.84 & 254.8 & 254.8 & 254.8 & 254.8 \\
\hline 10 & 6.24 & 6.24 & 18.72 & 28.08 & 49.92 & 149.76 & 299.52 & 332.8 \\
\hline 10 & 41.6 & 149.76 & 168.48 & 168.48 & 187.2 & 254.8 & 280.28 & 331.24 \\
\hline 10 & 1.04 & 18.72 & 65 & 131.04 & 131.04 & 149.76 & 168.48 & 187.2 \\
\hline $10+$ TSA & 78 & 131.04 & 229.32 & 229.32 & 229.32 & 254.8 & 254.8 & 280.28 \\
\hline $10+$ TSA & 131.04 & 131.04 & 266.24 & 266.24 & 299.52 & 332.8 & 332.8 & 399.36 \\
\hline $10+$ TSA & 131.04 & 178.36 & 299.52 & 299.52 & 299.52 & 421.2 & 421.2 & 572 \\
\hline 21 & 6.24 & 41.6 & 58.24 & 104 & 149.76 & 229.32 & 332.8 & 463.32 \\
\hline 21 & 0.52 & 1.04 & 4.16 & 6.24 & 14.04 & 78 & 78 & 149.76 \\
\hline 21 & 4.16 & 4.16 & 14.04 & 65 & 112.32 & 149.76 & 254.8 & 366.08 \\
\hline $21+$ TSA & 6.24 & 14.04 & 4.16 & 14.04 & 41.6 & 91 & 91 & 104 \\
\hline $21+$ TSA & 18.72 & 18.72 & 18.72 & 41.6 & 41.6 & 78 & 78 & 104 \\
\hline $21+\mathrm{TSA}$ & 4.16 & 4.16 & 4.16 & 4.16 & 4.16 & 4.16 & 18.72 & 78 \\
\hline
\end{tabular}

C1 - control group; C2 - control group - intratumor injection (DMSO+PBS); C3 - control group - intratumor injection with TSA; 5 - formulation No. 5; 5+TSA - formulation No. 5 with TSA; 18 - formulation No. 18; 18+TSA - formulation No. 18 with TSA; 10 - formulation No. 10; $10+$ TSA - formulation No. 10 with TSA; 21 - formulation No. 21; 21+TSA - formulation No. 21 with TSA.

on a recognized international volumetric method, which provides confirmed and well-confirmed measurements of skin hydration. ${ }^{32,33}$ The findings of the Corneometer are presented in contract units. The higher the values, the drier and less moisturized skin. The effect of the tumor and its growth, and the effect of intratumor injection and TSA on skin moisturizing were not confirmed. As presented in Fig. 3, the measurement of skin moisture with Corneometer showed that the tumor growth and treatment with TSA and non-TSA formulations had no effect on the skin condition. The Tewameter probe was used to assess TEWL without impairing the skin microenvironment.
The Tewameter probe is based on the open-chamber diffusion technique (sensors of temperature and relative humidity), where the gradient of the water evaporation from the skin is measured according to Fick's law and is expressed as evaporation coefficient in $\mathrm{g} / \mathrm{h} / \mathrm{m}^{2}$. The Tewameter probe is a reliable tool to measure water evaporation from the skin. ${ }^{34}$ The higher the result, the greater water loss and worse skin condition. The skin on the tumor shows similar humidity to the skin near the tumor that has not been treated with formulations. Figure 4 shows that the epidermal barrier function of neoplastic tumors has been reduced. The measurement with the Tewameter 

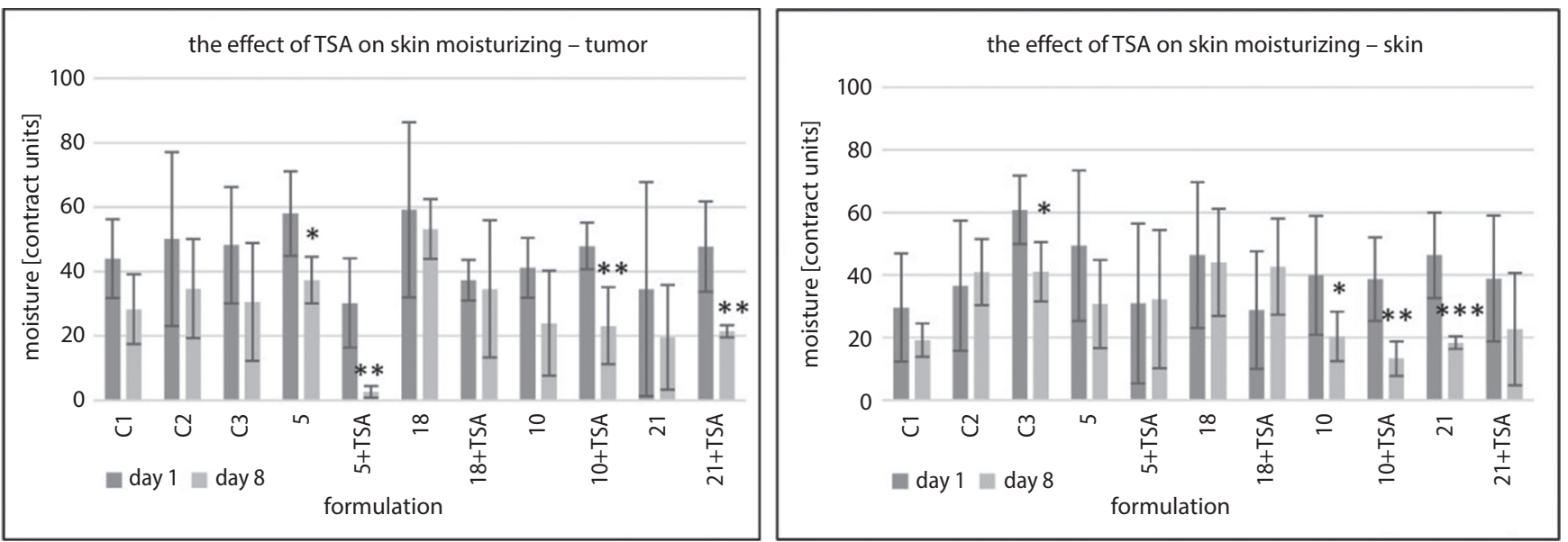

Fig. 3. Assessment of anticancer activity of semisolid TSA formulations in Balb/c mice with L1 tumor. Assessment of skin moisture. Measurement with the Corneometer probe $(n=10)$

C1 - control group; C2 - control group - intratumor injection (DMSO+PBS); C3 - control group - intratumor injection with TSA; 5 - formulation No. 5; 5+TSA - formulation No. 5 with TSA; 18 - formulation No. 18; 18+TSA - formulation No. 18 with TSA; 10 - formulation No. 10; $10+T S A$ - formulation No. 10 with TSA; 21 - formulation No. 21; 21+TSA - formulation No. 21 with TSA. Statistically significant differences are marked with an asterisk (* p < 0.05; $\left.{ }^{* *} p<0.01 ;{ }^{* * *} p<0.001\right)$.
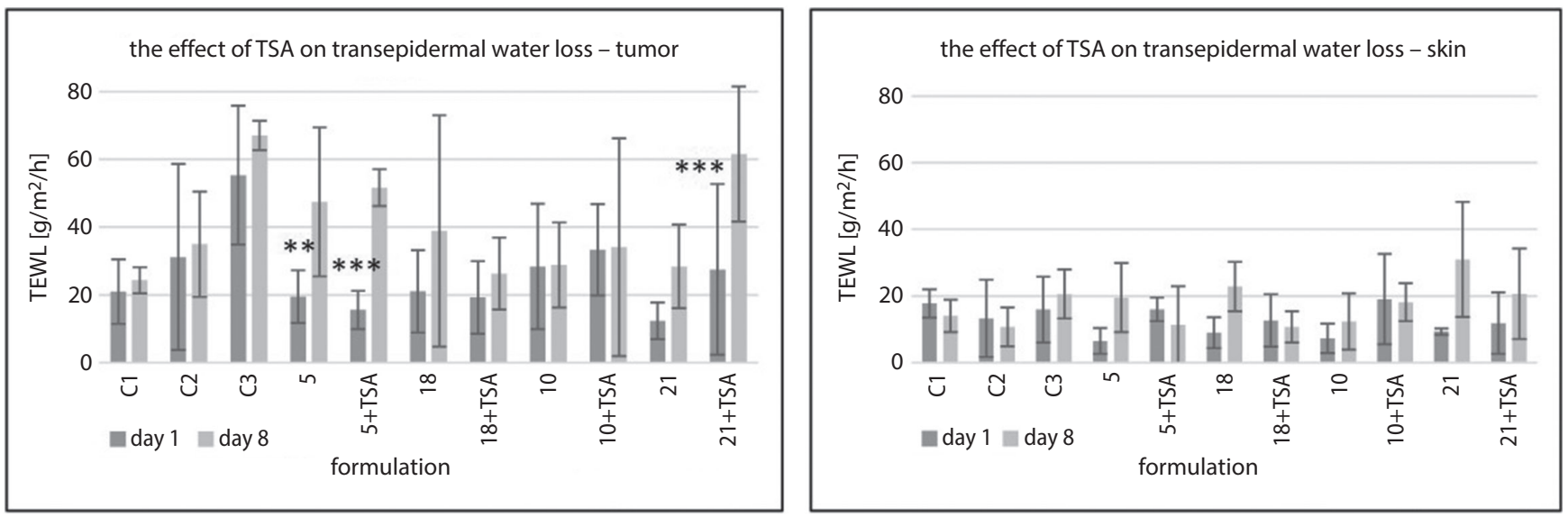

Fig. 4. Assessment of anticancer activity of semisolid TSA formulations in Balb/c mice with L1 tumor. Assessment of transepidermal water loss (TEWL). Measurement with the Tewameter probe $(n=5)$ with standard deviation (SD) of 0.2

C1 - control group; C2 - control group - intratumor injection (DMSO+PBS); C3 - control group - intratumor injection with TSA; 5 - formulation No. 5; 5+TSA - formulation No. 5 with TSA; 18 - formulation No. 18; 18+TSA - formulation No. 18 with TSA; 10 - formulation No. 10; $10+$ TSA - formulation No. 10 with TSA; 21 - formulation No. 21; 21+TSA - formulation No. 21 with TSA. Statistically significant differences are marked with an asterisk ${ }^{* *} p<0.01$; *** $p<0.001)$.

probe indicates that the water loss through tumor skin is higher in comparison with the skin on the areas not treated with the formulations.

\section{Discussion}

Currently, the experimental research in the field of innovative anticancer drugs are focused on the search for new active substances and are significantly associated with the development of effective carriers and strategies for drug transfer. Recently, research has also been performed on new drug forms for known active substances in order to extend the therapeutic indications of registered medicines. This study is part of the current research on medicines. ${ }^{37-39}$ The aim of the experiment was to obtain a preparation with antitumor activity for external use. The excipients used in the pharmaceutical formulation were selected, as well as new multiphase substrates with liposomes or based on polymers. A semi-solid formulation with a histone deacetylase inhibitor, TSA, was prepared. The antitumor activity of the preparation was evaluated in a model of transplantable L1 tumor in Balb/c laboratory mice. The available sources of scientific research are reporting that much research has been conducted in the field of histone deacetylase (HDAC) inhibition over the past decade. ${ }^{40-42}$ The HDAC inhibitors (HDACi) have high anticancer potential. The HDACi (e.g., vorinostat, panobinostat, belinostat) approved by the Federal Drug Administration (FDA) are used for treatment of various types 
of cancer. ${ }^{42}$ Many HDACi (e.g., entinostat) are in clinical research phase. ${ }^{42,43}$ The HDACi present anti-tumor activity through various mechanisms, i.e., cell cycle arrest, induction of apoptosis and autophagy in transformed cells, and inhibition of angiogenesis. ${ }^{42,44}$ The growing interest of HADACi because of their effectiveness in cancer therapy encourages the search and research of other substances that belong to this group. ${ }^{40}$ It has been confirmed that TSA is a reversible HDAC inhibitor and affects cancer cells by activating apoptotic pathways and arresting the cell cycle. Induction of apoptosis occurs through external (death receptor) or internal (mitochondrial) pathways; both of them lead to caspase activation and cell death induction. ${ }^{16,44}$ In the study by Ma et al., TSA has been shown to have antiproliferative activity on cells of the esophageal squamous cell carcinoma line by inducing cell cycle arrest and apoptosis. ${ }^{45}$ It seems that TSA can be considered as an anticancer active substance to use in the preparation of semi-solid formulations for external application in cancer. Studies show that known anticancer substances, e.g., vismodegib, imiquimod, 5-fluorouracil, methotrexate, or gabapentin, applied topically are helpful in the treatment of cancer. ${ }^{46-52}$ In one of the first studies which proposed a local application of vismodegib, developed by Calienni et al., nanoformulation in the treatment of basal-cell cancer was obtained. Vismodegib was incorporated into liposomes to provide a local nanodrug delivery system that may be useful in reducing systemic distribution and, as a consequence, side effects, while simultaneously penetrating the stratum corneum. ${ }^{46}$ Kubicki et al. reported complete remission of primary cutaneous anaplastic large cell lymphoma after topical application of imiquimod. ${ }^{47}$ Another study showed that 5\% imiquimod for topical use is an acceptable treatment option for patients with malignant melanoma who prefer local treatment over surgery or radiation therapy. ${ }^{48} \mathrm{~A}$ mouse model study found that methotrexate encapsulated in liposomes administered topically may be a new, less toxic treatment opportunity for human psoriasis. ${ }^{49}$ On the other hand, a study by Shahid et al. showed that gabapentin can also be used topically, but not as an antitumor substance, but to treat neuropathic pain. The study demonstrated that both local and systemic administration of gabapentin to rats weakens peripheral neuropathy caused by chemotherapy. Topical use of gabapentin may be an auxiliary or alternative way of treating neuropathic pain when administration of systemic drugs threatens the patient's life due to side effects. ${ }^{50}$ In the study by Kanaya et al., patients with ocular surface squamous neoplasia after local tumor resection were locally treated with interferon $\alpha-2 b$. Topical administration of interferon $\alpha-2 b$ contributed to inhibiting tumor recurrence and improving the patients' quality of vision. ${ }^{51}$ Another study showed that topically applied interferon $\alpha-2 b$ in the form of eye drops is an effective and safe treatment for conjunctival papilloma. Three months after the start of treatment with interferon $\alpha-2 b$, complete regression of the lesion was achieved..$^{52}$ In the treatment of cancer, combination therapy is extremely important. This approach of treatment takes advantage of the fact that anticancer substances can more effectively inhibit tumor growth in combination with radiation and/or another anticancer substances, which suggests a promising strategy in the treatment of skin metastases. Topical application of imiquimod cream simultaneously with radiation therapy significantly reduced the growth of a breast cancer tumor in a mouse model, compared to using these therapies separately. Moreover, administration of cyclophosphamide prior to imiquimod and radiation therapy potentiates the therapeutic effect, suggesting that this combination is a very promising strategy for metastases of breast cancer to the skin. ${ }^{53}$

In the current study, it was important to choose the right formulation to achieve proper TSA release. It is known that skin permeability is increased due to the presence of water, which causes swelling of keratin and increases intercellular spaces. Semi-solid preparations that form an occlusive layer on the skin also increase the hydration of the stratum corneum and the absorption of drugs through the skin. ${ }^{54}$ Therefore, semi-solid preparations were selected for in vivo studies that released TSA well and those with occlusive properties: the o/w emulsion with a thickening and stabilizing substance (hydroxypropylmethylcellulose), the w/o emulsion on an absorbenthydrophobic medium, the hydrogel with propylene glycol (which increases the penetration of the formulation through the skin and prolongs the stability of the preparation), and the o/w emulsion gel based on polymers and almond oil was used. As Fig. 5 shows, it was observed that the growth of tumors treated with TSA preparations was lower than the growth in the control groups (without TSA). Anticancer activity of topical preparations was also noticed in other works on HDAC inhibitors. In the study

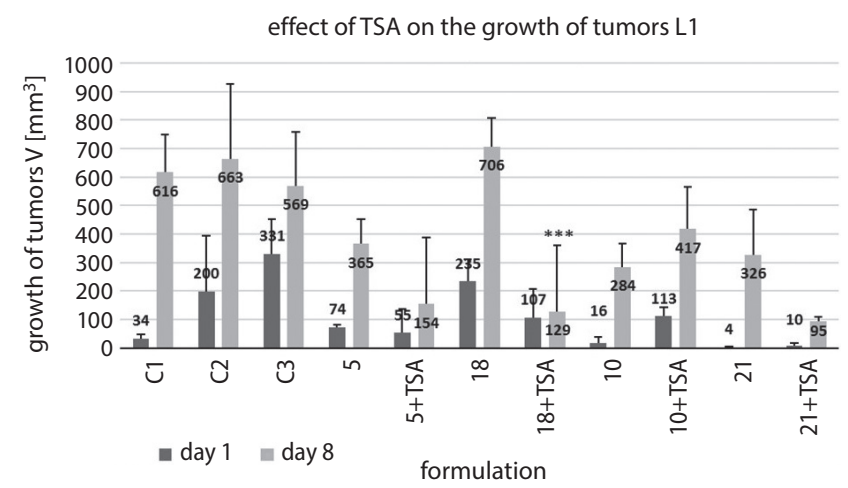

Fig. 5. Assessment of anticancer activity of semisolid TSA formulations in Balb/c mice with L1 tumor

C1 - control group; C2 - control group - intratumor injection (DMSO+PBS); C3 - control group - intratumor injection with TSA; 5 - formulation No. 5; 5+TSA - formulation No. 5 with TSA; 18 - formulation No. 18;

18+TSA - formulation No. 18 with TSA; 10 - formulation No. 10; 10+TSA - formulation No. 10 with TSA; 21 - formulation No. 21; 21+TSA - formulation No. 21 with TSA. Statistically significant differences are marked with an asterisk (*** $p<0.001)$. 
performed by Dai et al., a hydrogel with vorinostat was used on rats. ${ }^{55}$ The purpose of this study was to develop a new formulation with vorinostat that would be effective in the early stages of cutaneous $\mathrm{T}$ cell lymphoma and free of serious side effects. As a result, topical administration with a much lower dose showed a higher area under the curve (AUC) (cumulative amount of vorinostat retention through the skin) than oral administration, and the hydrogel achieved sustained permeation of vorinostat in the skin for $24 \mathrm{~h}$ in vivo. This indicated that higher relative bioavailability of vorinostat from the hydrogel was achieved compared to oral route. Researchers found that a hydrogel can deliver vorinostat to local skin more effectively and without adverse effects than oral administration. A study performed by Dai et al. confirms that the topical application of the preparation to the skin achieves higher availability of the active substance and additionally reduces the adverse effects of the treatment. ${ }^{55}$ These results encourage the search for new substances that can be used in the same way, but there is also a need to suggest new/ appropriate formulations for topical application. Another study used entinostat (MS-275), which at a concentration of $2 \mathrm{mg} / \mathrm{kg}$ significantly slowed the growth of squamous cell carcinoma of the skin in a hairless SKH-1 mouse model. MS-275 was cell-permeable as a topical preparation and induced changes in histone acetylation in mouse tumor tissue. It was also effective in inhibiting the proliferation of patient-derived squamous cell carcinoma lines and was especially effective towards cells isolated from regional metastases in an immunocompromised individual. ${ }^{43}$

\section{Conclusions}

In summary, the performed research indicates that tumor growth may be limited through external administration of active substances with histone deacetylase inhibitory activity. This study provides useful information for planning future clinical protocols in oncology. The formulations for topical use with TSA can be considered as future preparations supporting the treatment of patients with cancer. It is also worth noting that the non-invasive, external route of application of prescription semi-solid formulations allows the patient to use the medicinal preparation outside the clinic. According to the results of the performed research on external applications, we recommend o/w emulsion pharmaceutical formulations based on hydroxypropylmethylcellulose and SEPINEO P600/almond oil.

\section{ORCID iDs}

Agnieszka Chodkowska (D) https://orcid.org/0000-0002-8920-1057

Alicja Bieńkowska (D) https://orcid.org/0000-0002-7675-0428

Żaneta Słyk (D) https://orcid.org/0000-0002-1178-7908

Joanna Giebułtowicz (D) https://orcid.org/0000-0002-2567-4453

Maciej Małecki (D) https://orcid.org/0000-0002-7078-4918

\section{References}

1. International Agency for Research on Cancer. https://gco.iarc.fr/ tomorrow/home. Accessed August 24, 2020.

2. Krajowy Rejestr Nowotworów. http://onkologia.org.pl/nowotworyzlosliwe-ogolem-2/. Accessed August 24. 2020.

3. Chessum N, Jones K, Pasqua E, Tucker M. Recent advances in cancer therapeutics. Prog Med Chem. 2015;54:1-63. doi:10.1016/bs.pmch. 2014.11.002

4. Collins I, Workman P. New approaches to molecular cancer therapeutics. Nat Chem Biol. 2006;2(12):689-700.

5. Grabarska A, Dmoszyńska-Graniczka M, Nowosadzka E, Stepulak A. Histone deacetylase inhibitors: Molecular mechanisms of actions and clinical applications. Postepy Hig Med Dosw (Online). 2013;67: 722-735.

6. Smith LT, Otterson GA, Plass C. Unraveling the epigenetic code of cancer for therapy. Trends Genet. 2007;23(9):449-456.

7. Kudo K, Ozaki T, Shin-ya K, Nishiyama M, Kuzuyama T. Biosynthetic origin of the hydroxamic acid moiety of trichostatin A: Identification of unprecedented enzymatic machinery involved in hydroxylamine transfer. J Am Chem Soc. 2017;139(20):6799-6802. doi:10.1021/ jacs.7b02071

8. Tsuji N, Kobayashi M, Nagashima K, Wakisaka Y, Koizumi K. A new antifungal antibiotic, trichostatin. J Antibiot (Tokyo). 1976;29(1):1-6. doi.org/10.7164/antibiotics.29.1

9. Yoshida M, Horinouchi S, Beppu T. Trichostatin A and trapoxin: Novel chemical probes for the role of histone acetylation in chromatin structure and function. Bioessays. 1995;17(5):423-430. doi:10.1002/ bies.950170510

10. Kim SH, Kang HJ, Na H, LiMO. Trichostatin A enhances acetylation as well as protein stability of ERalpha through induction of p300 protein. Breast Cancer Res. 2010;12(2):R22. doi:10.1186/bcr2562

11. Sharma P, Kumar S, Kundu GC. Transcriptional regulation of human osteopontin promoter by histone deacetylase inhibitor, trichostatin A in cervical cancer cells. Mol Cancer. 2010;9:178. doi:10.1186/1476-45989-178

12. Cheng DD, Yang QC, Zhang ZC, Yang CX, Liu YW. Antitumor activity of histone deacetylase inhibitor trichostatin $\mathrm{A}$ in osteosarcoma cells. Asian Pac J Cancer Prev. 2012;13(4):1395-1399. doi:10.7314/apjcp. 2012.13.4.1395

13. Park H, Lee YJ, Kim TH, et al. Effects of trichostatin A, a histone deacetylase inhibitor, on the regulation of apoptosis in $\mathrm{H}$-ras-transformed breast epithelial cells. Int J Mol Med. 2008;22(5):605-611.

14. Geng Y, Liu J, Xie Y, et al. Trichostatin A promotes GLI1 degradation and P21 expression in multiple myeloma cells. Cancer Manag Res. 2018;10:2905-2914. doi:10.2147/CMAR.S167330

15. Hakami NY, Dusting GJ, Peshavariya HM. Trichostatin A, a histone deacetylase inhibitor suppresses NADPH oxidase 4-derived redox signaling and angiogenesis. J Cell Mol Med. 2016;20(10):1932-1944. doi:10.1111/jcmm.12885

16. Hajji N, Wallenborg $K$, Vlachos $P$, Nyman U, Hermanson $O$, Joseph $B$. Combinatorial action of the HDAC inhibitor trichostatin $A$ and etoposide induces caspase-mediated AIF-dependent apoptotic cell death in non-small cell lung carcinoma cells. Oncogene. 2008;27(22): 3134-3144.

17. Wu J, Hu CP, Gu QH, Li YP, Song M. Trichostatin A sensitizes cisplatinresistant $\mathrm{A} 549$ cells to apoptosis by up-regulating death-associated protein kinase. Acta Pharmacol Sin. 2010;31(1):93-101. doi:10.1038/ aps.2009.183

18. Zhang XF, Yan Q, Shen W, Gurunathan S. Trichostatin A enhances the apoptotic potential of palladium nanoparticles in human cervical cancer cells. Int J Mo/ Sci. 2016;17(8):1354. doi:10.3390/ijms17081354

19. Suraweera $A, O^{\prime} B y r n e K J$, Richard DJ. Combination therapy with histone deacetylase inhibitors (HDACi) for the treatment of cancer: Achieving the full therapeutic potential of HDACi. Front Oncol. 2018;8:92. doi:10.3389/fonc.2018.0009

20. Ghiciuc CM, Strat AL, Ochiuz L, et al. Inhibition of bcl-2 and cox-2 protein expression after local application of a new carmustine-loaded clinoptilolite-based delivery system in a chemically induced skin cancer model in mice. Molecules. 2017;22(11):2014. doi:10.3390/molecules22112014 
21. Shakeel F, Haq N, Al-Dhfyan A, Alanazi FK, Alsarra IA. Chemoprevention of skin cancer using low HLB surfactant nanoemulsion of 5-fluorouracil: A preliminary study. Drug Deliv. 2015;22(4):573-580. doi:10. 3109/10717544.2013.868557

22. Pharmacopoea Polonica Editio XI. Vol. I. Warszawa, Poland: Polskie Towarzystwo Farmaceutyczne; 2017:122.

23. Sznitowska M. Farmacja stosowana. Technologia postaci leku. Warszawa, Poland: PZWL; 2017;369-442, 883-930.

24. Seppic SA. https://www.seppic.com/en/technologies/polymerization. Accessed August 24, 2020.

25. Bonacucina G, Cespi M, Palmieri GF. Characterization and stability of emulsion gels based on acrylamide/sodium acryloyldimethyl taurate copolymer. AAPS PharmSciTech. 2009;10(2):368-375. doi:10.1208/ s12249-009-9218-1

26. Janik P, Szaniawska B. Search for an influence of natural immunity on the lung colony assay of a syngeneic transplanted murine tumour. Br J Cancer. 1978;37(6):1083-1085. doi:10.1038/bjc.1978.157

27. Vigushin DM, Ali S, Pace PE, et al. Trichostatin A is a histone deacetylase inhibitor with potent antitumor activity against breast cancer in vivo. Clin Cancer Res. 2001;7(4):971-976.

28. Ali NS, Akudugu JM, Howell RH. A preliminary study on treatment of human breast cancer xenografts with a cocktail of paclitaxel, doxorubicin, and 131I-anti-epithelial cell adhesion molecule (9C4). World J Nucl Med. 2019;18(1):18-24. doi:10.4103/wjnm.WJNM_9_18

29. Tomayko MM, Reynolds CP. Determination of subcutaneous tumor size in athymic (nude) mice. Cancer Chemother Pharmacol. 1989;24(3):148-154. doi:10.1007/bf00300234

30. https://www.courage-khazaka.de/en/scientific-products/all-products/ 16-wissenschaftliche-produkte/alle-produkte/183-corneometer-e. Accessed August 24, 2020.

31. https://www.courage-khazaka.de/en/scientific-products/all-products/ 16-wissenschaftliche-produkte/alle-produkte/257-tewameter-hex-e. Accessed August 24, 2020.

32. Lodén $M$, Hagforsen $E$, Lindberg $M$. The presence of body hair influences the measurement of skin hydration with the Corneometer. Acta Derm Venereol. 1995;75(6):449-450. doi:10.2340/0001555575449450

33. Wakeman MP. An open-label forearm-controlled pilot study to assess the effect of a proprietary emollient formulation on objective parameters of skin function of eczema-prone individuals over 14 days. Clin Cosmet Investig Dermatol. 2017;10:275-283. doi:10.2147/CCID.S135841

34. De Paepe K, Houben E, Adam R, Wiesemann F, Rogiers V. Validation of the VapoMeter, a closed unventilated chamber system to assess transepidermal water loss vs the open chamber Tewameter. Skin Res Technol. 2005;11(1):61-69. doi:10.1111/j.1600-0846.2005.00101.x

35. Lunter DJ, Daniels R. New film forming emulsions containing Eudragit ${ }^{\circledR}$ NE and/or RS 30D for sustained dermal delivery of nonivamide. Eur J Pharm Biopharm. 2012;82(2):291-298.

36. Dyja $R$, Jankowski $A$. The effect of additives on release and in vitro skin retention of flavonoids from emulsion and gel semisolid formulations. Int J Cosmet Sci. 2017;39(4):442-449. doi:10.1111/ics.12395

37. Sarkar R, Banerjee S, Amin SA, Adhikari N, Jha T. Histone deacetylase 3 (HDAC3) inhibitors as anticancer agents: A review. Eur J Med Chem. 2020;192:112171. doi:10.1016/j.ejmech.2020.112171

38. Pucci C, Martinelli C, Ciofani G. Innovative approaches for cancer treatment: Current perspectives and new challenges. Ecancermedicalscience. 2019;13:961. doi:10.3332/ecancer.2019.961

39. Stoff JA. Selected office-based anticancer treatment strategies. J Oncol. 2019;2019:7462513. doi:10.1155/2019/7462513
40. Zhang $\mathrm{H}$, Shang YP, Chen HY, Li J. Histone deacetylases function as novel potential therapeutic targets for cancer. Hepatol Res. 2017; 47(2):149-159. doi:10.1111/hepr.12757

41. Schizas D, Mastoraki A, Naar L, et al. Concept of histone deacetylases in cancer: Reflections on esophageal carcinogenesis and treatment. World J Gastroenterol. 2018;24(41):4635-4642. doi:10.3748/wjg.v24. i41.4635

42. Singh AK, Bishayee A, Pandey AK. Targeting histone deacetylases with natural and synthetic agents: An emerging anticancer strategy. Nutrients. 2018;10(6):731. pii: E731. doi:10.3390/nu10060731

43. Kalin JH, Eroglu A, Liu $\mathrm{H}$, et al. Investigation into the use of histone deacetylase inhibitor MS-275 as a topical agent for the prevention and treatment of cutaneous squamous cell carcinoma in an $\mathrm{SKH}-1$ hairless mouse model. PLoS One. 2019;14(3):e0213095. doi:10.1371/ journal.pone.0213095

44. Sanaei M, Kavoosi F. Histone deacetylases and histone deacetylase inhibitors: Molecular mechanisms of action in various cancers. Adv Biomed Res. 2019;8:63. doi:10.4103/abr.abr_142_19

45. Ma J, Guo X, Zhang S, et al. Trichostatin A, a histone deacetylase inhibitor, suppresses proliferation and promotes apoptosis of esophageal squamous cell lines. MolMed Rep. 2015;11(6):4525-4531. doi:10.3892/ mmr.2015.3268

46. Calienni MN, Febres-Molina C, Llovera RE, et al. Nanoformulation for potential topical delivery of Vismodegib in skin cancer treatment. Int J Pharm. 2019;565:108-122. doi:10.1016/j.ijpharm.2019.05.002

47. Kubicki SL, Park KE, Aung PP, Duvic M. Complete resolution of primary cutaneous anaplastic large cell lymphoma with topical imiquimod. J Drugs Dermatol. 2019;18(5):460-462.

48. Tio DCKS, van Montfrans C, Ruijter CGH, Hoekzema R, Bekkenk MW. Effectiveness of $5 \%$ topical imiquimod for lentigo maligna treatment. Acta Derm Venereol. 2019;99(10):884-888. doi:10.2340/00015555-3241

49. Bahramizadeh $M$, Bahramizadeh $M$, Kiafar B, et al. Development, characterization and evaluation of topical methotrexateentrapped deformable liposome on imiquimod-induced psoriasis in a mouse model. Int J Pharm. 2019;569:118623. doi:10.1016/j. ijpharm.2019.118623

50. Shahid M, Subhan F, Ahmad N, Sewell RDE. Efficacy of a topical gabapentin gel in a cisplatin paradigm of chemotherapy-induced peripheral neuropathy. BMC Pharmacol Toxicol. 2019;20(1):51. doi:10.1186/ s40360-019-0329-3

51. Kanaya R, Kase S, Ishijima K, Ishida S. Usefulness of topical interferon alpha-2b eye drop as an adjunctive therapy following surgical resection in ocular surface squamous neoplasia. In Vivo. 2019;33(6):22112215. doi:10.21873/invivo.11724

52. Bolek B, Wylęgała A, Teper S, Kokot J, Wylęgała E. Treatment of conjunctival papilloma with topical interferon alpha-2b: Case report. Medicine (Baltimore). 2020;99(7):e19181. doi:10.1097/MD.0000000 000019181

53. Dewan MZ, Vanpouille-Box C, Kawashima N, et al. Synergy of topical toll-like receptor 7 agonist with radiation and low-dose cyclophosphamide in a mouse model of cutaneous breast cancer. Clin Cancer Res. 2012;18(24):6668-6678. doi:10.1158/1078-0432.CCR-12-0984

54. Sznitowska M, Kaliszan R. Biofarmacja. Wrocław, Poland: Elsevier Urban \& Partner; 2014:221-234.

55. Dai W, Wang C, Yu C, et al. Preparation of a mixed-matrix hydrogel of vorinostat for topical administration on the rats as experimental model. Eur J Pharm Sci. 2015;78:255-263. doi:10.1016/j.ejps.2015.07.019 